\title{
Relationship between urban heat island effect and land use in Taiyuan City,China
}

\author{
Shu Ting $\mathrm{LI}^{1}$, Jia $\mathrm{LI}^{1, \mathrm{a}}$ and Ping DUAN ${ }^{1}$ \\ ${ }^{1}$ School of tourism and geographical science, Yunnan normal university, Kunming, China
}

\begin{abstract}
The land surface temperature is inversed by Landsat remote sensing images of 2000, 2009 and 2015 years in Taiyuan, China. The mono-window algorithm is used to remove the influence of the atmosphere. The land surface thermal radiation intensity is obtained by the mono-window algorithm. Then the land surface true temperature is converted by the land surface thermal radiation intensity. At the same time, the remote sensing images of Taiyuan city in three time periods are classified by supervised classification method. Finally, the relationship between different years of Taiyuan land surface temperature and land use change is analysed. The results show that Taiyuan city land surface temperature is positively correlated with land use. The land surface temperature is higher when the land is frequently used. Taiyuan city land surface temperature is negatively correlated with vegetation coverage. The land surface temperature is lower when the higher vegetation is covered in the area.
\end{abstract}

\section{Introduction}

Urban thermal environment influenced by the earth's surface physical properties and human social economic activities, it is the comprehensive summary of urban ecological environment and reflect ${ }^{[1]}$. In recent years, under the background of global warming and the highspeed urbanization process, urban thermal environment is considered to be one of the dominant elements of the city environment, it has a profound impact on urban public health, air quality, energy consumption, etc ${ }^{[2]}$. Due to the characteristics of urban heat reflects through the form of electromagnetic radiation, thus can be directly detected by means of remote sensing, it is also become the basic principle of thermal remote sensing detection of urban thermal environment ${ }^{[3]}$. There are many factors that can cause of urban heat island effect: human activities, the underlying ground structure, vegetation coverage, and so on. To study the changes of Taiyuan urban heat island effect in recent 15 years, combing with the land use classification. To better illustrate the relationship between human activities and the urban heat island effect, and gives some corresponding solutions.

\section{The research area}

Taiyuan is the capital of SHANXI Province. It is located in Taiyuan Basin, the northern section of the, central and southern plains, East by the TAIHANG Mountains, West LVLIANG, the overall high terrain north south, East and west across $114 \mathrm{~km}$, north-south span is about $107 \mathrm{KM}$. The whole Taiyuan have GUJIAO, QINGXU, YANGQU, LOUFAN four counties (cities), and WANBAILIN area, YINGZE district, XINGHUALING district, JIANCAOPING district, JINYUAN district of six main area, the total area of 6959 $\mathrm{km} 2$ in the whole city area, the total population of 4.2565 million.(2012). The climate of Taiyuan city is the temperate zone monsoon climate, large temperature difference between day and night, ample sunshine ${ }^{[4]}$.

\section{METHODS}

The calculation method of surface temperature inversion, the radiation brightness temperature is calculated and estimate the atmosphere on the effects of surface radiation brightness, using a single thermal infrared channel with Landsat. Thus the performance surface true temperature. Firstly, the image is calibrated by radiometric calibration and atmospheric correction. The method adopted is FLAASH's own ENVI5.1 atmospheric correction module, which can effectively remove the influence of the atmosphere on the earth surface albedo, and get the true surface reflectance. Mono-window algorithm is Tan Zhihao. (2004) according to the surface thermal radiation conduction equation, deduces data by Landsat TM/ETM +6 band surface temperature inversion algorithm ${ }^{[5-6]}$. The formula for calculation is as follows:

$T_{s}=\left[a(1-C-D)+(b(1-C-D)+C+D) T_{6}-D T_{a}\right] / C$

\footnotetext{
a Jia LI : keguigiser@163.com
} 
In the formula, $T_{s}$ is the surface temperature, $a$ and $b$ are constants, are respectively 67.355351 and 0.458606 , $C=\varepsilon \tau, D=(1-\tau)[1+(1-\varepsilon) \tau], \varepsilon$ is the surface emissivity, $\mathrm{T}$ atmospheric transmittance.

The infrared brightness value received by the satellite sensor is composed of three parts: Atmospheric radiation brightness upwards, the energy of the earth's surface, which passes through the atmosphere, reaches the satellite sensor, atmospheric radiation reaches the ground down after the reflected energy. Announced on NASA's website (http://atmcorr.gsfc.nasa.gov), input image's time and center longitude and latitude, can get the atmospheric transmittance, atmospheric radiation brightness upward, atmospheric radiation brightness down three parameters. The radiative transfer equations is as follows:

$$
L_{\lambda}=\left[\varepsilon B\left(T_{S}\right)+(1-\varepsilon) L \downarrow\right] \tau+L \uparrow
$$

In the formula, $\varepsilon$ is surface emissivity, $T_{s}$ is the surface temperature, $B\left(T_{s}\right)$ as the blackbody radiation brightness, $T$ for atmospheric transmittance. Blackbody temperature is $T$ in the thermal infrared radiation intensity $B(T s)$ :

$$
B\left(T_{S}\right)=\left[L_{\lambda}-L \uparrow-\tau(1-\tau) L \downarrow\right] / \tau \varepsilon
$$

In the formula, $T_{s}$ can be obtained by the formula of Planck's radiation law.

$$
T_{S}=K_{2} / \operatorname{In}\left(K_{1} / B\left(T_{2}\right)+1\right)
$$

In the formula, for Landsat TM, $K_{1}=607.76$ $\mathrm{W} /\left(\mathrm{m}^{2} * \mu \mathrm{m} * \mathrm{sr}\right), K_{2}=1206.56 \mathrm{k}$; for TIRS Band10, $K_{1}=$ $774.89 \mathrm{~W} /\left(\mathrm{m}^{2} * \mu \mathrm{m}^{*} \mathrm{sr}\right), K_{2}=1321.08 \mathrm{k}$.

The NDVI threshold method proposed by Sobrino is used to calculate the surface emissivity:

$$
\varepsilon=0.004 P_{\mathrm{v}}+0.986
$$

In the formula, $P_{v}$ is vegetation coverage, Calculating formula is:

$$
P_{\mathrm{v}}=\left[\left(N D V I-N D V I_{\text {Soil }}\right) /\left(N D V I_{\text {Veg }}-N D V I_{\text {Soil }}\right)\right]
$$

In the formula, $N D V I$ is the normalized difference vegetation index, $N D V I_{\text {Soil }}$ is the $N D V I$ value of no vegetation or completely bare soil, $N D V I_{V e g}$ is the $N D V I$ value of completely covered by vegetation. Remote sensing image characterizes terrestrial object by brightness value and the pixel value and the spatial change. This is the physical basis of distinguishing different image features ${ }^{[7]}$. It is through the unique differences that can distinguish objects on the same image. Remote sensing image classification have supervised classification and unsupervised classification, it is the use of different spectral information and spatial information, and then each pixel is classified according to a certain rule.

Supervised classification is used in this paper, Select a certain number of training samples in remote sensing image, to carry out statistical or other information. After choosing the supervision of the support vector machine (SVM) classifier for classification image, SVM can automatically search for the support vector which has a large capacity for classification. Thus the separator constructed can maximize the distance between the class and class, and having a good classification accuracy. This article using the method of supervised classification to classify the land in Taiyuan City, in ARCGIS, the land use classification figure transformation, get vector boundary files, to the area of different land types. In ENVI software statistical analysis of different types of land surface temperature, get the average temperature of the different land types.

\section{Conclusion analysis}

\subsection{Characteristics of urban heat island in Taiyuan}

Taiyuan city administrative region plan as shown in figure 1, There are six municipalities directly under the jurisdiction of Taiyuan: JIANCAOPING district, WAN BAILIN district, JINYUAN district, XINGHUALING district, YINGZE district,Xi district. LOUFAN country and YANGQY country have a sparse population and natural vegetation coverage rate is relatively high, GUJIAO is Taiyuan energy heavy chemical industry base, QINGXU is main crop growth area in TAIYUAN ${ }^{[8]}$.

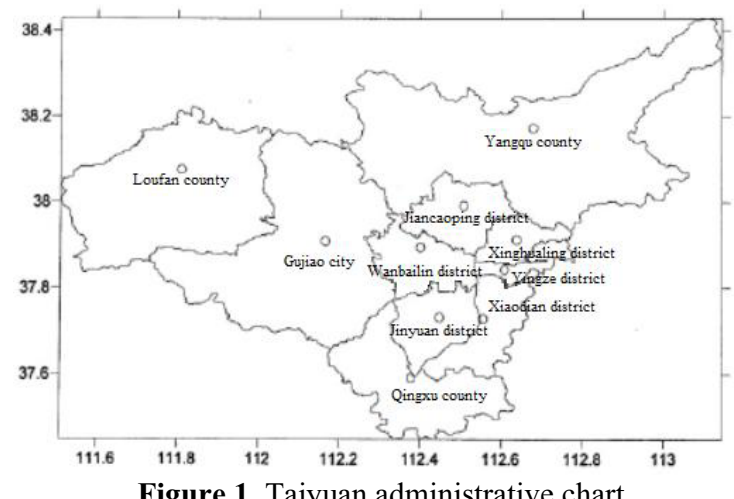

In this paper, the surface temperature of Taiyuan city is retrieved by remote sensing image of Taiyuan city in August 2009 and August 2000 in September 2015. The results are as follows:

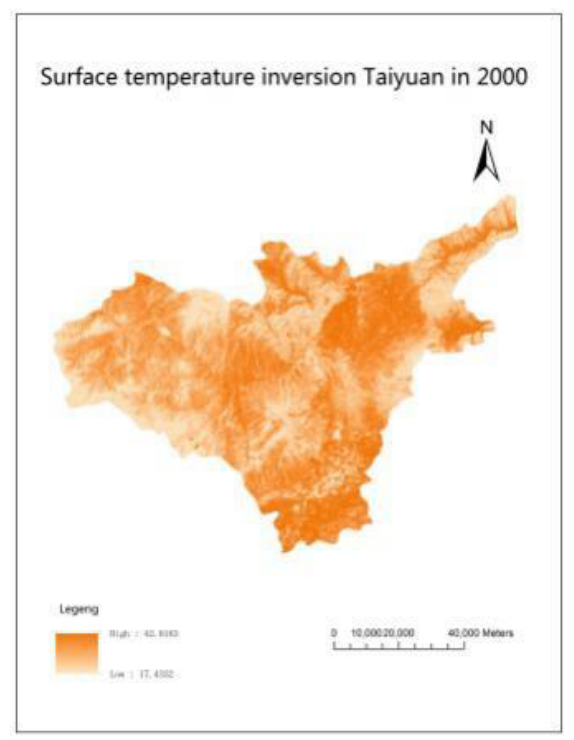



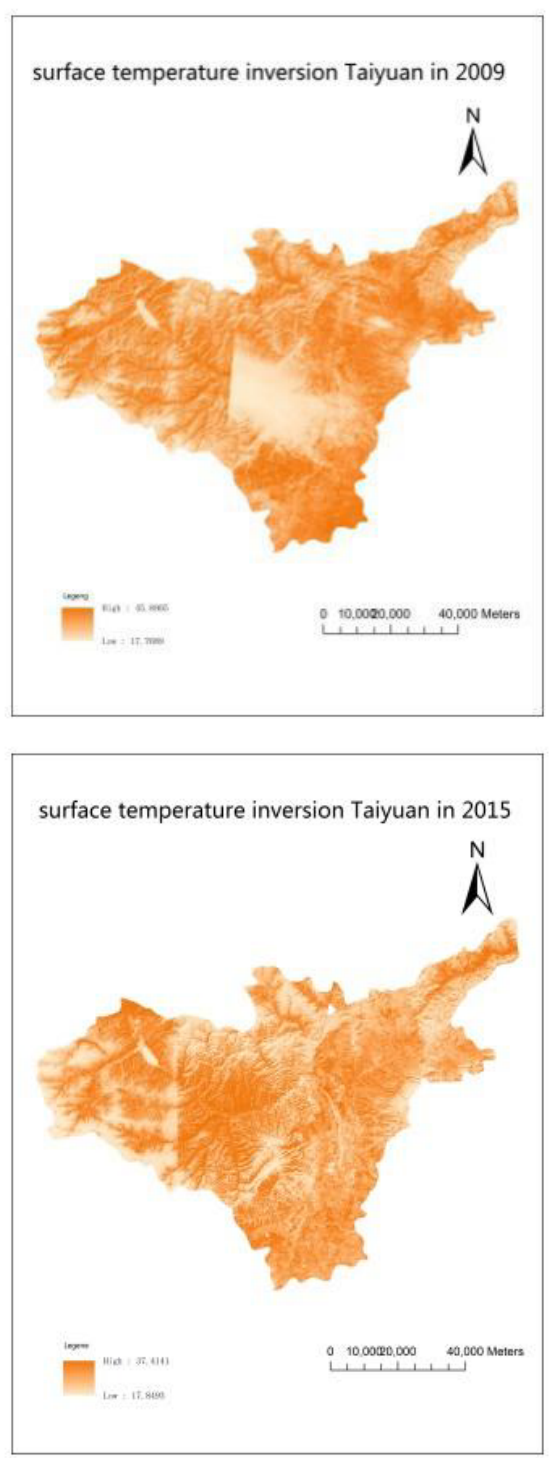

Figure 2. Surface temperature inversion 2000-2015 in Taiyuan

As seen in the figure, the surrounding temperature is higher in Taiyuan 2000, in 2009, due to the reasons of the image, it is not to be able to show it very well. But it can be seen that the temperature is higher in JIANCAOPING district. In 2000, QINGXU County's temperature has decreased. Taiyuan city high temperature region in 2009 has increased than 2000, heat island effect is more obvious. QINGXU county temperature decreased.

\subsection{Analysis of urban heat island and land change in Taiyuan}

There are several reasons for the emergence of the urban heat island: underlying surface structure, urban landscape, vegetation coverage, etc. It is one of the most closely related to human activities, through the comparison of land use planning in 2000, 2009 and 2015, explain that the emergence of the urban heat island has close relationship with human activity.
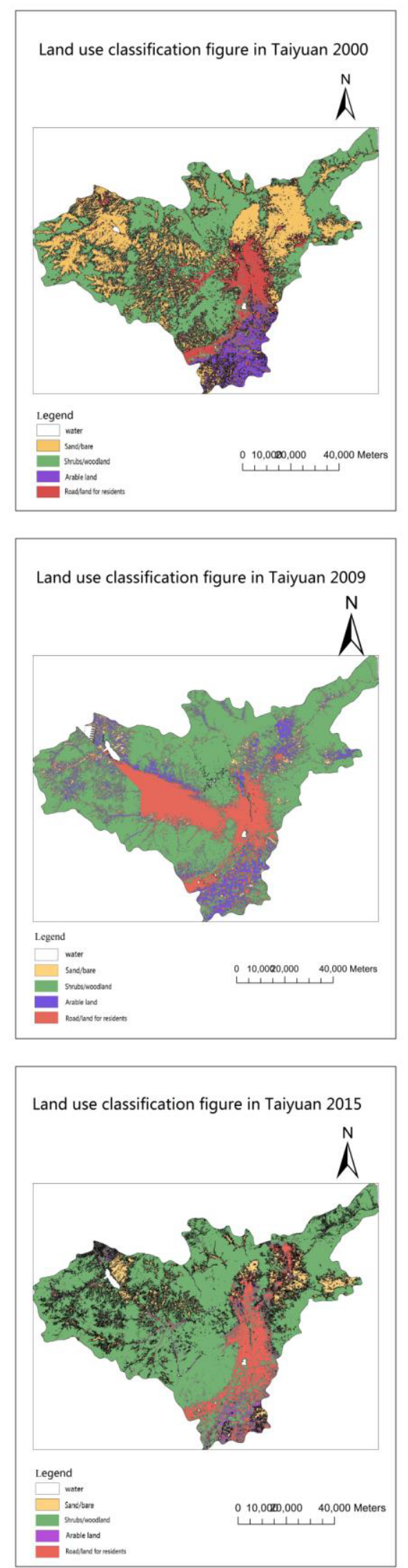

Figure 3. Land use classification 2000-2015 in Taiyuan

In addition to the image has a problem in 2009 , It can be seen that Sand/bare land is more in 2000, in 2015, the area of the sand/bare land accounts for obvious less than in 2000. Impervious surface (road/residential land) in the 
2000-2015 years is constant expansion trend. Combining with the land surface temperature inversion figure in 2000-2015, TAIYUAN city high temperature area is increasing, and has a tendency to expand outward. Combined with the above figure, found that most high temperature areas of TAIYUAN city are bare land/sand and the ridge. The following figure used the ARCGIS, it is the statistical analysis of the $2000-2015$ Taiyuan City Road / residential that different land type area changes in line chart:

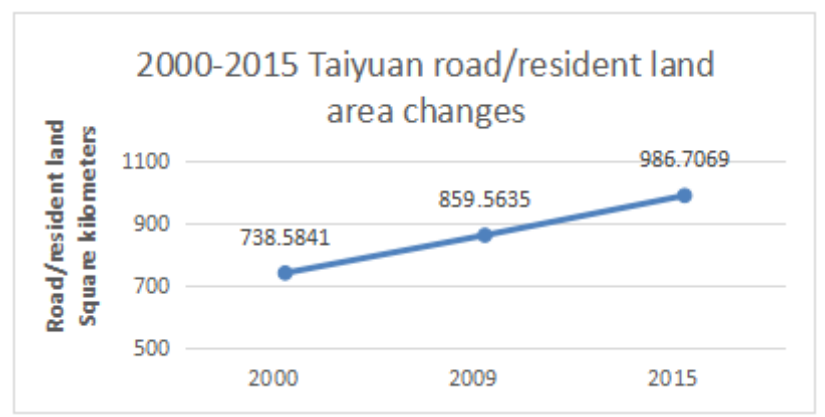

Figure 4 2000-2015 Taiyuan road/resident land are changes

Through by 2000 and 2015 remote sensing images of land use / cover types of surface temperature statistics analysis, we can see that Taiyuan City 2015 sand / bare area significantly reduced $23.8 \%$, shrub / forest land occupied area ratio increased $18.85 \%$ road / residents with added $3.57 \%$, it is indicates that the city still has expansion, and the average temperature of the road / resident is increased by 1.31 Centigrade. From 20002015, Taiyuan economy is developing fast, urban land area changed little,at the same time increased the vegetation construction, driven by economic development, urban heat island effect more obvious (because image reasons in 2009, there is no do statistical analysis)

Table 1. Surface average temperature of land cover type

\begin{tabular}{lcccc}
\hline \multirow{1}{*}{$\begin{array}{c}\text { Surface } \\
\text { type }\end{array}$} & $\begin{array}{c}\text { 2000 } \\
\text { Proportion } \\
\text { of area } / \%\end{array}$ & $\begin{array}{c}\text { average } \\
\text { temperatu } \\
\text { re } /{ }^{\circ} \mathrm{C}\end{array}$ & $\begin{array}{c}\text { Proportio } \\
\text { n of area } \\
/ \%\end{array}$ & $\begin{array}{c}\mathbf{2 0 1 5} \\
\text { average } \\
\text { temperatu } /{ }^{\circ} \mathrm{C}\end{array}$ \\
\hline 1 sand/bare & 37.32 & 36.62 & 13.52 & 34.69 \\
$\begin{array}{l}\text { 2shrubs/woodl } \\
\text { and }\end{array}$ & 45.69 & 26.04 & 64.81 & 29.44 \\
3arable land & 6.04 & 23.38 & 7.14 & 34.7 \\
$\begin{array}{l}\text { 4residential } \\
\text { land }\end{array}$ & 10.61 & 32.74 & 14.18 & 34.05 \\
\hline
\end{tabular}

\section{5 conclusion}

There are many factors cause urban heat island effect: artificial construction of urban land use planning, which will change the city underlying surface structure, thus will change the underlying surface properties; a large number of industrial emissions and vehicle emissions, these heat emitted in the air, will make the city's temperature increased. So urban heat island effect has a close relationship with human activities, is caused by human beings. Daniel believes that in the climate of the state, the urbanization and industrial pollution will cause downstream of the rainfall and snowfall increased ${ }^{[9]}$.Sang Jianguo and other found that in the winter is also the heat effect of forcing effect, that urban heat island effect is easy to form a low pressure system for the center of the city as well as the direction of the city center pressure gradient force ${ }^{[10]}$.It not only affects the environment of human life, but also has a great impact on human health.Urban heat island effect are also associated with vegetation coverage,research shows that the green coverage rate is higher, the lower the intensity of the heat island,when the coverage is more than $30 \%$, heat island effect obviously weakened; coverage is more than $50 \%$, the green space is extremely obvious to the reduction of heat island effect.In the city, planting more trees and the construction of the park, urban heat island effect will be eased. The wind also can reduce the quantity of heat. It will be in the urban planning design construction direction, and it is beneficial to the formation of the wind that will reduce heat in the city. The most important thing is the human activity, human reducing emissions of heat, it is also important measures that reduce heat island formation.

\section{References}

1. X.L. Zhang, S.W. Zhang, Y. Li, Y.F. Xie, W.H. Kuang, J. Resour Sci 30, 390(2008)

2. J. Zhang, X.P. Zhang, X.Y. Wang, J.M. Zhang,Y. Liu, Y. Xiao, Arid Land Geog 33, 51(2010)

3. G.L. Tian, Publishing House of Electronics Industry(2006)

4. Shanxi Statistical Bureau. Shanxi statistical yearbook (2012)

5. Z.Q. Lv, Y. Wen., Z. Sun, J. Acta Ecol Sin 19,1771(2010)

6. Z.H. Tan, W.J. Li, M.H. Zhang, J. RS for Land \& Resour 23, 33(2002)

7. S.B. Deng., Envi remote sensing image processing method (Second Edition)

8. Y.H. Li, Z.C. Li, J.H. Zhou, C.P. Zhao, Journal of Arid Land Resour and Environ 12,173 (2013)

9. Rosenfeld. D, J. Sci 287,1793(2000)

10. J.G. Sang, W.J. Liu, J. Acta Meteoro Sinica 48, 459(1990) 